\title{
Risk Factors for the Development Versus Maintenance of Posttraumatic Stress Disorder
}

\author{
Paula P. Schnurr, ${ }^{1,2,4}$ Carole A. Lunney, ${ }^{1}$ and Anjana Sengupta ${ }^{1,2,3}$
}

\begin{abstract}
This study examined risk factors for posttraumatic stress disorder (PTSD) in Vietnam veterans: 68 women and 414 men of whom 88 were White, 63 Black, 80 Hispanic, 90 Native Hawaiian, and 93 Japanese American. Continuation ratio logistic regression was used to compare the predictive power of risk factors for the development versus maintenance of full or partial PTSD. The development of PTSD was related to premilitary, military, and postmilitary factors. The maintenance of PTSD was related primarily to military and postmilitary factors. Multivariate analyses identified different models for development and maintenance. We conclude that development of PTSD is related to factors that occur before, during, and after a traumatic event, whereas failure to recover is related primarily to factors that occur during and after the event.
\end{abstract}

KEY WORDS: posttraumatic stress disorder; military veterans; longitudinal course; risk factors.

Risk of developing posttraumatic stress disorder (PTSD) varies with a number of pretraumatic, peritraumatic, and posttraumatic factors (e.g., Breslau, Davis, Andreski, \& Peterson, 1991; Kessler, Sonnega, Bromet, Hughes, \& Nelson, 1995; Resnick, Kilpatrick, Dansky, Saunders, \& Best, 1993; Schnurr, Friedman, \& Rosenberg, 1993). Risk of chronic PTSD, as reflected by a diagnosis of current PTSD among individuals whose exposure occurred many years prior, also is related to many of the same risk factors (e.g., King, King, Fairbank, Keane, \& Adams, 1998; King, King, Foy, \& Gudanowski, 1996; Kulka et al., 1990; Schnurr \& Vielhauer, 1999; Stein, Walker, Hazen, \& Forde, 1997). Yet very few investigations of risk factors for PTSD have attempted to distinguish chronic from less chronic PTSD. In fact, a recent meta-analysis combined studies of current and lifetime

\footnotetext{
${ }^{1}$ Department of Veterans Affairs National Center for PTSD, VA Medical Center, White River Junction, Vermont.

${ }^{2}$ Dartmouth Medical School, Hanover, New Hampshire.

${ }^{3}$ New Hampshire-Dartmouth Psychiatric Research Center, 2 Whipple Place, Lebanon, New Hampshire.

${ }^{4}$ To whom correspondence should be addressed at National Center for PTSD (116D), VA Medical Center, White River Junction, Vermont 05009; e-mail: paula.schnurr@ dartmouth.edu.
}

PTSD because of this limitation of the existing literature (Brewin, Andrews, \& Valentine, 2000). Consequently, we know little about which factors are associated with the $d e$ velopment of PTSD, as compared with the maintenance of PTSD. Such information has important implications for both theory and treatment.

Studies of risk factors for lifetime PTSD yield information about the development of PTSD. Studies of risk factors for current chronic PTSD can yield information about maintenance if a comparison group without current PTSD is restricted to individuals who had PTSD in the past only. (If a comparison group also includes individuals who never had PTSD, risk factors for development are confounded with risk factors for maintenance.) Thus, comparisons between studies of risk factors for lifetime PTSD and studies of risk factors for current chronic PTSD can suggest which factors are associated with development and which are associated with maintenance. A limitation of this approach is that these comparisons are indirect.

Another indirect approach is to examine the relative strength of predictors at different times. For example, Dunmore, Clark, and Ehlers (2001) studied assault survivors within 4 months after an assault, and then 6 and 9 months after the initial assessment. Assault type was 
related to PTSD symptoms at initial assessment but not at either follow-up, whereas preassault psychological difficulties were related to PTSD severity at 9 months. This suggests that type of assault is important in the development of PTSD, and pretraumatic problems are important in maintenance.

The most direct approach to understanding development versus maintenance is to compare individuals who developed short-term PTSD with individuals who developed chronic PTSD. North, Smith, and Spitznagel (1997) found that neither demographic characteristics, pretraumatic and acute psychiatric comorbidities, nor exposure characteristics, predicted remission in survivors of a mass shooting who were interviewed 6-8 weeks and 1 year later. McFarlane (1988) also reported negative findings in a study of firefighters who were assessed 4-, 11-, and 29-month postfire. McFarlane (1992) also examined the 8-month symptom profiles of firefighters whose PTSD had remitted at 42 months and firefighters who still had PTSD. The only difference was a greater likelihood of concentration difficulties in the chronic group.

Dunmore, Clark, and Ehlers (1999) compared chronic and remitted cases of PTSD due to physical and sexual assault. Chronic cases had less education and were less likely to have been married at the time of the assault, although groups were similar in marital status at interview. Chronic cases also were less likely than remitted cases to have pretraumatic emotional problems, but chronic cases had greater PTSD symptoms in the month following the assault. The chronic group was more likely than the remitted group to report life threat and injury threat and to have been involved in legal action related to the assault. Cognitive factors were strongly associated with the maintenance of PTSD: mental defeat, confusion, and negative appraisals of emotions and actions during the assault; negative appraisals of initial symptoms; perceptions of permanent change; avoidant symptom control strategies; and negative global beliefs after the assault.

Breslau and Davis (1992) compared trauma survivors whose PTSD lasted less than 1 year (acute) with those whose PTSD lasted 1 year or more (chronic). Relative to the acute group, the chronic group had more women and persons with lifetime affective or anxiety disorders. The chronic group also had greater lifetime prevalence of distress or physiological reactivity to traumatic reminders, numbing, and concentration difficulties. The acute and chronic groups did not differ in type of trauma. In analyses that separately compared each group with survivors who never developed PTSD, factors identified as predictors of chronic PTSD but not acute PTSD were female gender, family history of antisocial behavior, preexisting anxiety or depression, and neuroticism. Blanchard et al.
(1997) studied accident victims who had PTSD or partial PTSD when assessed after the accident. Comparing those whose PTSD had remitted 6 months after the initial assessment with those who still had PTSD, Blanchard et al. found that continued PTSD was associated with higher initial PTSD severity, more severe injury, a greater amount of injury remaining at 4 months, and familial trauma after the accident. Green, Grace, Lindy, and Gleser (1990) examined war stressors in male Vietnam veterans, comparing lifetime PTSD versus never PTSD groups, and current PTSD versus never and past only PTSD groups. The lifetime PTSD group reported more exposure than the never PTSD group on all variables except two that distinguished the current PTSD group from the others: exposure to death and mutilation and a higher number of special assignments.

\section{The Present Study}

Findings from the few studies that have directly compared chronic and remitted cases of PTSD indicate that individuals who develop chronic PTSD differ from those who recover on factors such as gender, amount and type of trauma exposure (including injury and atrocity exposure), initial symptom severity, and exposure to subsequent trauma. This study was designed to replicate and extend these findings by using a comprehensive set of pretraumatic, peritraumatic, and posttraumatic risk factors, and an analytic method that allowed statistical comparisons of the effects of these risk factors on the development and maintenance of PTSD. Our sample came from two large, ethnically diverse studies of Vietnam veterans: the National Vietnam Veterans Readjustment Study (NVVRS; Kulka et al., 1990) and the Hawaiian Vietnam Veterans Project (HVVP; Friedman et al., 1997), which was modeled on the NVVRS.

In primary analyses, to identify risk factors for the development of PTSD, we compared veterans who never had PTSD with veterans who had lifetime PTSD. To identify risk factors for the maintenance of PTSD, we compared veterans who had PTSD in the past only with veterans who had current PTSD. We also tested whether the effects of risk factors on these two outcomes differed. Secondary analyses used multivariate methods to develop models for predicting the development of PTSD and its maintenance. Full and partial PTSD categories were pooled to increase statistical power. Visual inspection of the data suggested that pooling was appropriate, but supplementary analyses were conducted excluding individuals with a partial diagnosis. Given the reduction in sample size, only univariate tests were performed for these analyses. 
We examined risk factors that had been implicated in prior research as related to lifetime or current chronic PTSD, focusing on variables that could apply to persons with and persons without PTSD. We followed the selection and creation of variables used in a series of studies that identified risk factors for current chronic PTSD in the NVVRS lay-interview sample (King et al., 1996, 1998; King, King, Foy, Keane, \& Fairbank, 1999). Onset of depression also was examined given findings on the role of depression in the development and maintenance of PTSD (e.g., Freedman, Brandes, Peri, \& Shalev, 1999).

\section{Method}

\section{Participants}

Kulka et al. (1990) collected the NVVRS data between 1987 and 1988 using a two-stage design to study a national probability sample of male and female Vietnam theater veterans, Vietnam era veterans, and civilians. In the first stage, lay interviews were conducted with 1,632 male and female Vietnam theater veterans, 716 era veterans who served during the Vietnam era but not in Vietnam, and 668 civilians; $n$ s reflect response rates of 83,76 , and $70 \%$, respectively. In the second stage, clinical interviews were conducted with 344 Vietnam theater veterans and 96 era veterans: all probable cases of PTSD plus a sample of probable noncases who were oversampled for high combat exposure; $n$ s reflect response rates of $85 \%$ among theater veterans and $83 \%$ among era veterans.

Friedman et al. (1997) collected the HVVP data between 1994 and 1996 using a two-stage design and methods similar to those employed in the NVVRS. The HVVP was restricted to male Native Hawaiians and Americans of Japanese Ancestry (AJA) who had served in the Vietnam theater and who resided in the State of Hawaii at the time of the study. Of 700 veterans targeted for the first stage, 302 Native Hawaiians (85\%) and 302 AJAs (87\%) completed the lay interview. For the clinical interview stage, 131 Native Hawaiian and 131 AJA veterans were selected; 100 Native Hawaiian (69\%) and 102 AJA (79\%) veterans completed the interview.

Participants in this study were 482 men and women who were selected from 546 Vietnam theater veterans in the NVVRS and HVVP clinical interview samples; only NVVRS theater veterans were included because the HVVP sample did not include era or civilian counterparts. Participants were selected because they had trauma exposure (by Criterion A from the SCID (Structured Clinical Interview for $D S M-I I I-R$ ) and/or premilitary, military, or postmilitary trauma counts; see below) and they had complete data on all variables with $<2 \%$ missing values. (Variables with $2 \%$ or more missing data included relationship with father [7.2\%], childhood antisocial behavior [2.1\%], peritraumatic dissociation [2.5\%], and onset of depression relative to Vietnam [3.5\%].)

The sample included 299 veterans from the NVVRS (68 women, 63 Black men, 80 Hispanic men, and 88 White/ other men) and 183 male veterans from the HVVP (90 Native Hawaiians and 93 AJA). The NVVRS and HVVP differed in the number of years elapsed since entering Vietnam, $t(480)=45.25, p<.001$. On average, HVVP participants were interviewed 26.9 years later (range $=$ 23-33). NVVRS participants were interviewed an average of 19.2 years later (range $=14-24$ ). However, the length of the observation period in the NVVRS was so long that is unlikely many new cases would have emerged, or existing cases would have remitted, if participants had been interviewed at the same time as HVVP participants. Also, a prior analysis of the NVVRS/HVVP data (Schnurr, Lunney, Sengupta, \& Waelde, 2003) found that all cases of lifetime full or partial PTSD in the HVVP occurred within the NVVRS observation period: the longest HVVP onset was 22 years after Vietnam entry, and the next longest was 13 years after.

At interview, $71.6 \%$ of participants were married $(n=345)$ and $83.0 \%(n=400)$ were currently working. Average age was 45.38 years $(S D=7.38$, range $=32-70)$. Participants did not differ on these variables from those excluded because of missing data.

\section{Measures}

\section{PTSD Diagnosis}

PTSD was assessed using the Structured Clinical Interview for DSM-III-R (SCID; Spitzer, Williams, Gibbon, $\&$ First, 1989). A diagnosis of full current or lifetime PTSD required at least one "B" symptom, three " $\mathrm{C}$ " symptoms, and two " $\mathrm{D}$ " symptoms coded as threshold in the relevant time frame. Current and lifetime partial PTSD were defined as either meeting the " $\mathrm{B}$ " criterion (at least one "B" symptom) and the "D" criterion (at least two "D" symptoms), or meeting the "B" criterion and having at least one " $\mathrm{C}$ " and one " $\mathrm{D}$ " symptom, in the relevant time frame (Schnurr et al., 1993). To increase statistical power, lifetime and current diagnoses were combined to create a single outcome measure coded "never" (no lifetime or current partial/full PTSD diagnosis), "past only" (lifetime partial or full PTSD but no current PTSD diagnosis), and "current" (current partial or full PTSD). 
Age at Interview

Age at interview was calculated from the date of the interview and date of birth. The year of the SCID interview was not available for the NVVRS dataset and was set to 1987 because most of NVVRS interviews were conducted in 1987.

\section{Premilitary Variables}

Gender/ethnicity was represented by five indicator variables: female, Black male, Hispanic male, Native Hawaiian male, American Japanese male, with White/ other male as the reference category. Premilitary education was represented by two indicator variables, high school and some college/college degree, with no high school degree as the reference category. Age at entry into Vietnam was represented in years.

The remaining premilitary scales were adapted from King et al. (1996, 1998). Differences in items available from the NVVRS and HVVP necessitated some changes, as noted below. Premilitary socioeconomic status was calculated as the average of two standardized variables: a 3point scale of how well off the family was and a 4-point scale of whether the family had a hard time making ends meet. A third item on the original scale asking about receipt of welfare or charity was not available for the HVVP.

Family instability was calculated as the mean of four standardized items about drinking, drug use, mental disorder, and contact with a mental health professional, scored as in King et al. (1996). (Only four of King et al.'s nine items were available in both NVVRS and HVVP studies.) The drinking, drug abuse, and mental disorder items were scored " 1 " if that item did not occur in the family, " 2 " if it involved a family member other than a parent, " 3 " if it occurred to a parent or parent substitute, and " 4 " if it involved both parents.

Severe punishment was derived from a question asking whether respondents were ever spanked or hit hard enough to produce bruises or marks, to cause them to stay in bed, or to require a physician's attention, and if so, by whom. It was scored as for the family instability scale. An item from King et al.'s (1996) scale asking about frequency of severe punishment was not available for HVVP.

Relationship with father consisted of a single item assessing the overall quality of the relationship. NVVRS respondents rated their relationship on a 9-point scale $(1=$ poor, $9=$ excellent $)$. The HVVP used a 5-point scale $(1=$ poor, $5=$ excellent). Because the HVVP labels matched the NVVRS labels for odd scale points, HVVP responses were recoded to match the NVVRS scale (e.g., $1=1,3=$ $5,5=9)$.
Childhood antisocial behavior consisted of a count of 15 items scored as threshold or true from the childhood antisocial behavior section of the SCID (Spitzer et al., 1989). One item, stealing when no one was around, was not used because of missing data.

Pre-Vietnam trauma consisted of a count of exposure to 10 categories of extremely stressful events such as serious accidents and physical assaults that occurred before the veteran's first tour in Vietnam. Multiple occurrences within a category were counted separately. Events were only included (1) if the individual was present or saw the aftermath of the event, and (2) if the individual or victim was severely or permanently ill, injured, or mutilated or in real danger of being killed or severely injured, or the victim died a traumatic death, or the victim was a close friend/family member or friend/acquaintance.

\section{Military Variables}

Serious injury consisted of the number of affirmative responses to five dichotomous items: injury in Vietnam, evacuation or hospitalization for injury in Vietnam, receipt of a Purple Heart, spending time in a military hospital for wounds or injuries upon return, or having a serviceconnected physical disability.

Warzone exposure was operationalized as four variables defined by King et al. (1996). Traditional combat consisted of 35 items assessing the frequency of exposure to situations such as firing a weapon in combat. One item from King et al.'s scale, "Were you ever evacuated or hospitalized for wounds or injuries during your tour," was excluded because of overlap with the serious injury measure. Exposure to atrocities/abusive violence consisted of nine items assessing involvement in situations such as terrorizing or killing hostages. Perceived life threat consisted of nine items assessing perceptions of exposure to threatening or harmful events such as the danger of being killed. Malevolent environment consisted of 18 items assessing exposure to irritations and pressures such as not having shelter from the weather. Items for each warzone measure were standardized prior to averaging.

Peritraumatic dissociation was measured with the 8item Peritraumatic Dissociative Experiences ScaleRater Version (Marmar et al., 1994). Items, rated $1=a b$ sent, $2=$ subthreshold, and $3=$ threshold, were averaged.

\section{Postmilitary Variables}

King et al.'s (1998) measures of structural and functional social support were modified slightly to permit examination of how aspects of social support relate to the 
development and maintenance of PTSD. Structural social support was computed as the average of two standardized items that were available in both NVVRS and HVVP datasets: "number of close friends/relatives" and "how often do you get together with friends/relatives?" Four scales were created from King et al.'s functional social support measure by separating the measure's components of emotional sustenance and instrumental assistance, and distinguishing between support at homecoming and interview. Homecoming emotional sustenance (average of five standardized items) consisted of questions about the reception veterans received upon return from Vietnam. Current emotional sustenance (average of seven standardized items) consisted of questions such as "Does it seem that your family and friends understand you?" Homecoming instrumental assistance (average of two standardized items) and current instrumental assistance (average of four standardized items) consisted of questions such as the availability of someone to lend money or visit regularly.

Post-Vietnam trauma was computed in the same way as pre-Vietnam trauma (see above) for those events that occurred after Vietnam service. Recent life events was computed as the sum of responses to 12 questions assessing exposure to nontraumatic stressors such as illness or financial difficulties in the year before interview.

\section{Depression}

For primary analyses, first onset of major depression symptoms (diagnosed from the SCID) was represented as three indicator variables: onset before, onset during, and onset after Vietnam, with no depression as the reference category. Secondary analyses examined onset of depression relative to onset of PTSD in participants with lifetime PTSD, using three indicator variables: onset before PTSD, onset the same year as PTSD onset, and onset after PTSD, with no depression as the reference category.

\section{Data Analysis}

Continuation ratio logistic regression (Hosmer \& Lemeshow, 2000) was used for the primary univariate analyses. This procedure compares the likelihood of each outcome category to all lower categories, allowing statistical comparison of risk factors for developing PTSD (never vs. ever) versus its maintenance (past only vs. current). Because these contrasts are independent, the equality of odds ratios (ORs) across models can be evaluated by $\chi^{2}$ test (Hosmer \& Lemeshow, 2000). Confidence intervals (CIs) were $95 \%$.
Next, two multiple stepwise logistic regressions were conducted for secondary analyses to predict (1) the development of PTSD, comparing "never" versus "ever" groups, and (2) the maintenance of PTSD, comparing "past only" versus "current" groups. Stepwise entry was used to efficiently screen individual predictors (Hosmer \& Lemeshow, 2000) because our goal was to determine the best-fitting model for each outcome rather than to test specific hypotheses about individual variables or sets of variables. For each analysis, all variables significant by univariate test at $p<.05$ were entered and deleted using backward elimination with $p$ for deletion set to .05 .

\section{Results}

Of the 482 veterans in the sample, $23.9 \%$ had current PTSD (current partial, $n=41$; current full, $n=74$ ), $25.5 \%$ had PTSD in the past only (lifetime partial, $n=59$; lifetime full, $n=64)$, and 50.6\% $(n=244)$ never had a partial or full PTSD diagnosis.

\section{Univariate Analyses}

Table 1 presents descriptive information about premilitary, military, and postmilitary variables as a function of PTSD diagnostic status. Table 2 presents the results of the univariate analyses predicting PTSD outcome from the premilitary, military, and postmilitary variables. All variables except pre-Vietnam trauma $(p=.058)$ were related to the development of PTSD. Higher risk of developing PTSD was associated with ethnicity (Hispanic vs. White), family instability, severe punishment, childhood antisocial behavior, warzone exposure, peritraumatic dissociation, recent life events, post-Vietnam trauma, and depression either before, during, or after Vietnam. Lower risk of developing PTSD was associated with Japanese American ethnicity (vs. White), a high school degree or college education (vs. less education), (older) age at Vietnam entry, (higher) socioeconomic status, (a more positive) paternal relationship, (more) social support at homecoming, and (more) current social support.

Fewer risk and protective factors were associated with the maintenance of PTSD. Of the premilitary variables, severe punishment was associated with higher risk, and Native Hawaiian or Japanese American ethnicity (vs. White) and a college education (vs. no degree), were associated with lower risk. All military variables were associated with higher risk of maintaining PTSD. Of the postmilitary variables, number of recent life events was associated with higher risk. Current structural social support, homecoming emotional sustenance, and current emotional 
Table 1. Premilitary, Military, and Postmilitary Risk Factors as a Function of PTSD Diagnostic Status in Vietnam Veterans $(n=482)$

\begin{tabular}{|c|c|c|c|}
\hline Risk factor & Never $(n=244)$ & Past only $(n=123)$ & Current $(n=115)$ \\
\hline \multicolumn{4}{|l|}{ Gender/ethnicity } \\
\hline White male & $53.4 \%(47)$ & $19.3 \%(17)$ & $27.3 \%(24)$ \\
\hline Female & $55.9 \%(38)$ & $25.0 \%(17)$ & $19.1 \%(13)$ \\
\hline Black male & $38.1 \%(24)$ & $31.7 \%(20)$ & $30.2 \%(19)$ \\
\hline Hispanic male & $36.3 \%(29)$ & $20.0 \%(16)$ & $43.8 \%(35)$ \\
\hline Native Hawaiian male & $42.2 \%(38)$ & $36.7 \%(33)$ & $21.1 \%(19)$ \\
\hline American Japanese male & $73.1 \%(68)$ & $21.5 \%(20)$ & $5.4 \%(5)$ \\
\hline \multicolumn{4}{|l|}{ Premilitary education } \\
\hline Less than high school degree & $35.1 \%(27)$ & $26.0 \%(20)$ & $39.0 \%(30)$ \\
\hline High school degree & $50.8 \%(122)$ & $25.8 \%(62)$ & $23.3 \%(56)$ \\
\hline Some college/college degree & $57.6 \%(95)$ & $24.8 \%(41)$ & $17.6 \%(29)$ \\
\hline Age at entry into Vietnam & $24.76(6.89)$ & $21.83(4.38)$ & $21.70(4.49)$ \\
\hline Pre-Vietnam trauma & $0.50(0.89)$ & $0.72(1.19)$ & $0.63(1.12)$ \\
\hline Premilitary socioeconomic status & $0.18(0.84)$ & $-0.18(0.87)$ & $-0.22(0.88)$ \\
\hline Family instability & $-0.08(0.53)$ & $0.15(0.78)$ & $0.08(0.72)$ \\
\hline Severe punishment & $1.23(0.66)$ & $1.36(0.78)$ & $1.59(0.95)$ \\
\hline Relationship with father & $6.34(2.21)$ & $6.04(2.46)$ & $5.73(2.54)$ \\
\hline Childhood antisocial behavior & $1.10(1.72)$ & $1.72(2.32)$ & $2.25(2.75)$ \\
\hline Traditional combat & $-0.24(0.47)$ & $0.20(0.56)$ & $0.41(0.63)$ \\
\hline Atrocities/abusive violence & $-0.28(0.43)$ & $0.14(0.70)$ & $0.56(0.92)$ \\
\hline Perceived life threat & $-0.28(0.55)$ & $0.23(0.57)$ & $0.47(0.58)$ \\
\hline Malevolent environment & $-0.28(0.55)$ & $0.24(0.54)$ & $0.46(0.58)$ \\
\hline Serious injury & $0.48(1.01)$ & $0.85(1.42)$ & $1.29(1.57)$ \\
\hline Peritraumatic dissociation & $1.28(0.33)$ & $1.76(0.55)$ & $1.98(0.49)$ \\
\hline Homecoming emotional sustenance & $0.26(0.64)$ & $-0.21(0.70)$ & $-0.44(0.67)$ \\
\hline Homecoming instrumental assistance & $0.16(0.68)$ & $-0.09(0.89)$ & $-0.27(0.99)$ \\
\hline Current emotional sustenance & $0.19(0.53)$ & $-0.04(0.69)$ & $-0.43(0.86)$ \\
\hline Current instrumental assistance & $0.15(0.50)$ & $-0.09(0.92)$ & $-0.27(1.14)$ \\
\hline Current structural social support & $0.07(0.75)$ & $0.002(0.78)$ & $-0.24(0.73)$ \\
\hline Post-Vietnam trauma & $1.18(1.34)$ & $1.94(1.79)$ & $2.18(2.16)$ \\
\hline Recent life events & $1.27(1.39)$ & $1.97(1.66)$ & $2.47(1.99)$ \\
\hline \multicolumn{4}{|l|}{ Depression onset } \\
\hline No depression diagnosis & $59.0 \%(204)$ & $23.4 \%(81)$ & $17.6 \%(61)$ \\
\hline Onset before Vietnam & $25.0 \%(4)$ & $37.5 \%(6)$ & $37.5 \%(6)$ \\
\hline Onset during Vietnam & $21.1 \%(4)$ & $26.3 \%(5)$ & $52.6 \%(10)$ \\
\hline Onset after Vietnam & $34.5 \%(29)$ & $33.3 \%(28)$ & $32.1 \%(27)$ \\
\hline
\end{tabular}

Note. PTSD categories include full and partial diagnoses. Standard deviations for means and frequencies for percentages are reported in parentheses. There are small amounts of missing data for some variables.

sustenance were protective. Contrary to expectation, depression relative to Vietnam entry was not a risk factor for maintaining PTSD, although onset during Vietnam was associated with marginally elevated risk $(p=$ $.089)$.

We also examined depression onset relative to PTSD onset among veterans with lifetime PTSD. Of these veterans, 5.4\% $(n=12)$ had depression onset before PTSD onset, 7.1\% $(n=16)$ had onset of depression and PTSD at the same age, and $24.1 \%(n=54)$ had depression onset after PTSD onset. Compared with veterans who had lifetime PTSD and no depression $(63.4 \% ; n=142)$, those who developed depression were not more likely to remain chronic, regardless of depression onset: $\mathrm{OR}=1.86$ for onset before PTSD $(\mathrm{CI}=0.56,6.14), \mathrm{OR}=2.21$ for onset at the same age $(\mathrm{CI}=0.76,6.42)$, and $\mathrm{OR}=1.23$ for onset after PTSD $(\mathrm{CI}=0.66,2.31)$.
There were statistically significant differences between some risk factors in terms of their relationship with the two PTSD outcomes (Table 2). Several risk factors were associated only with the development of PTSD: age at entry into Vietnam, premilitary socioeconomic status, family instability, current instrumental assistance, and post-Vietnam trauma. Other risk factors were associated with both PTSD outcomes, but had a larger effect on development than on maintenance: traditional combat, atrocity exposure, perceived life threat, malevolent environment, peritraumatic dissociation, homecoming emotional sustenance, and recent life events. Only one variable, Native Hawaiian ethnicity, was a significant predictor of maintenance but not development.

Univariate analyses excluding partial cases showed overall patterns that were highly similar to the patterns observed for analyses including partial cases. Results of 
Table 2. Univariate Analyses of Risk Factors for the Development and Maintenance of PTSD in Vietnam Veterans

\begin{tabular}{|c|c|c|c|c|c|}
\hline \multirow[b]{2}{*}{ Predictor } & \multicolumn{2}{|c|}{$\begin{array}{l}\text { Never vs. ever } \\
\quad(n=482)\end{array}$} & \multicolumn{2}{|c|}{$\begin{array}{l}\text { Past vs. current } \\
\quad(n=238)\end{array}$} & \multirow[b]{2}{*}{ Difference $^{a}$} \\
\hline & OR & $(95 \% \mathrm{CI})$ & OR & $(95 \% \mathrm{CI})$ & \\
\hline \multicolumn{6}{|l|}{ Gender/ethnicity (vs. White male) } \\
\hline Female & 0.91 & $(0.48,1.71)$ & 0.54 & $(0.21,1.40)$ & \\
\hline Black male & 1.86 & $(0.96,3.60)$ & 0.67 & $(0.28,1.63)$ & \\
\hline Hispanic male & $2.02^{*}$ & $(1.09,3.74)$ & 1.55 & $(0.66,3.65)$ & \\
\hline Native Hawaiian male & 1.57 & $(0.87,2.84)$ & $0.41^{*}$ & $(0.18,0.94)$ & * \\
\hline American Japanese male & $0.42^{* *}$ & $(0.23,0.78)$ & $0.18^{* *}$ & $(0.06,0.57)$ & \\
\hline \multicolumn{6}{|l|}{$\begin{array}{l}\text { Premilitary education } \\
\text { (vs. no high school) }\end{array}$} \\
\hline High school & $0.52^{*}$ & $(0.31,0.89)$ & 0.60 & $(0.31,1.18)$ & \\
\hline Some college/degree & $0.40^{* *}$ & $(0.23,0.70)$ & $0.47^{*}$ & $(0.23,0.99)$ & \\
\hline Age at entry into Vietnam & $0.91^{* * *}$ & $(0.88,0.94)$ & 0.99 & $(0.94,1.05)$ & ** \\
\hline Pre-Vietnam trauma & 1.19 & $(0.99,1.43)$ & 0.94 & $(0.75,1.18)$ & \\
\hline Premilitary socioeconomic status & $0.61^{* * *}$ & $(0.49,0.75)$ & 0.94 & $(0.71,1.26)$ & * \\
\hline Family instability & $1.64^{* *}$ & $(1.22,2.21)$ & 0.89 & $(0.63,1.25)$ & ** \\
\hline Severe punishment & $1.52^{* * *}$ & $(1.19,1.94)$ & $1.37^{*}$ & $(1.01,1.84)$ & \\
\hline Relationship with father & $0.92^{*}$ & $(0.85,1.00)$ & 0.95 & $(0.85,1.06)$ & \\
\hline Childhood antisocial behavior & $1.22^{* * *}$ & $(1.11,1.34)$ & 1.08 & $(0.98,1.21)$ & \\
\hline Traditional combat & $6.05^{* * *}$ & $(4.09,8.93)$ & $1.80^{* *}$ & $(1.17,2.78)$ & $* * *$ \\
\hline Atrocities/abusive violence & $5.07^{* * *}$ & $(3.45,7.46)$ & $1.89^{* * *}$ & $(1.35,2.64)$ & $* * *$ \\
\hline Perceived life threat & $6.56^{* * *}$ & $(4.46,9.64)$ & $2.08^{* *}$ & $(1.31,3.25)$ & $* * *$ \\
\hline Malevolent environment & $6.94^{* * *}$ & $(4.68,10.31)$ & $2.04^{* *}$ & $(1.28,3.26)$ & $* * *$ \\
\hline Serious injury & $1.44^{* * *}$ & $(1.24,1.69)$ & $1.22^{*}$ & $(1.02,1.45)$ & \\
\hline Peritraumatic dissociation & $19.52^{* * *}$ & $(11.05,34.47)$ & $2.20^{* *}$ & $(1.33,3.63)$ & $* * *$ \\
\hline Homecoming emotional sustenance & $0.28^{* * *}$ & $(0.21,0.38)$ & $0.61^{*}$ & $(0.42,0.89)$ & ** \\
\hline Homecoming instrumental assistance & $0.59^{* * *}$ & $(0.47,0.75)$ & 0.81 & $(0.62,1.07)$ & \\
\hline Current emotional sustenance & $0.38^{* * *}$ & $(0.27,0.52)$ & $0.52^{* * *}$ & $(0.36,0.74)$ & \\
\hline Current instrumental assistance & $0.53^{* * *}$ & $(0.38,0.74)$ & 0.84 & $(0.65,1.09)$ & * \\
\hline Current structural social support & $0.72^{* *}$ & $(0.56,0.91)$ & $0.65^{*}$ & $(0.46,0.92)$ & \\
\hline Post-Vietnam trauma & $1.41^{* * *}$ & $(1.24,1.60)$ & 1.07 & $(0.93,1.21)$ & $* *$ \\
\hline Recent life events & $1.44^{* * *}$ & $(1.27,1.62)$ & $1.16^{*}$ & $(1.01,1.34)$ & * \\
\hline \multicolumn{6}{|l|}{ Depression onset (vs. no depression) } \\
\hline Onset before Vietnam & $4.31^{*}$ & $(1.36,13.63)$ & 1.33 & $(0.41,4.32)$ & \\
\hline Onset during Vietnam & $5.39^{* *}$ & $(1.75,16.57)$ & 2.66 & $(0.86,8.17)$ & \\
\hline Onset after Vietnam & $2.73^{* * *}$ & $(1.66,4.48)$ & 1.28 & $(0.69,2.39)$ & \\
\hline
\end{tabular}

Note. PTSD diagnoses include full and partial categories. There are small amounts of missing data for some variables. OR = odds ratio; $\mathrm{CI}=$ confidence interval.

${ }^{a}$ Asterisks in this column indicate statistical significance of the difference between odds ratios.

${ }^{*} p<.05 .{ }^{* *} p<.01 .^{* * *} p<.001$.

analyses to predict the development of lifetime PTSD were unchanged, except that the OR for American Japanese ancestry became marginally significant $(p<.10)$. The exclusion of partial cases resulted in two differences in the analyses to predict the maintenance of PTSD: college education became nonsignificant and homecoming instrumental assistance became significant $(\mathrm{OR}=0.66$, $p<.05$ ). In the analyses to compare the effects of risk factors on developing versus maintaining PTSD, the exclusion of partial cases resulted in four previously significant differences becoming nonsignificant: age at entry into Vietnam $(p<.10)$, premilitary socioeconomic status, family instability $(p<.10)$, and recent life events $(p<.10)$. Also, differences between ORs emerged for three variables: childhood antisocial behavior $(p<.05)$, depression onset before Vietnam $(p<.01)$, and depression onset after Vietnam $(p<.05)$.

\section{Multivariate Analyses}

Table 3 displays the results of multiple regressions to predict the development and maintenance of PTSD. The final model for development, which had good sensitivity and very good specificity, included premilitary socioeconomic status, perceived life threat, peritraumatic dissociation, homecoming emotional sustenance, and post-Vietnam trauma. The final model for maintenance included gender/ethnicity, atrocity exposure, and current emotional sustenance. The model had acceptable sensitivity and good specificity. 
Table 3. Results of Stepwise Logistic Regression Analyses to Predict the Development and Maintenance of PTSD in Vietnam Veterans

\begin{tabular}{|c|c|c|c|}
\hline \multicolumn{2}{|c|}{ PTSD outcome: never vs. ever $(n=416)$} & \multicolumn{2}{|c|}{ PTSD comparison: past vs. current $(n=233)$} \\
\hline Risk factor & Odds ratio & Risk factor & Odds ratio \\
\hline Premilitary socioeconomic status & $0.70^{*}$ & Gender/ethnicity (vs. White male) & \\
\hline Perceived life threat & $4.61^{* * *}$ & Female & 1.23 \\
\hline Peritraumatic dissociation & $13.21^{* * *}$ & Black male & 0.56 \\
\hline Homecoming emotional sustenance & $0.45^{* * *}$ & Hispanic male & 1.57 \\
\hline Post-Vietnam trauma & $1.21^{*}$ & Native Hawaiian male & $0.35^{*}$ \\
\hline & & American Japanese male & $0.14^{* *}$ \\
\hline & & Atrocities/abusive violence & $1.77^{* *}$ \\
\hline & & Current emotional sustenance & $0.44^{* * *}$ \\
\hline Accuracy $=81.3 \%$ & & Accuracy $=70.4 \%$ & \\
\hline Sensitivity $=77.5 \%$ & & Sensitivity $=64.3 \%$ & \\
\hline Specificity $=84.7 \%$ & & Specificity $=76.0 \%$ & \\
\hline
\end{tabular}

Note. PTSD diagnoses include full and partial categories.

${ }^{*} p<.05 .{ }^{* *} p<.01 .{ }^{* * *} p<.001$.

\section{Discussion}

We separately examined factors associated with the development and maintenance of PTSD. Results of univariate analyses were consistent with those from other studies showing that the development of PTSD is associated with numerous premilitary, military, and postmilitary factors (e.g., Green et al., 1990; King et al., 1998). The maintenance of PTSD was associated with ethnicity, lower premilitary education, more severe punishment, a higher amount of warzone exposure, peritraumatic dissociation, lower social support at homecoming, lower current social support, and a higher number of recent life events.

In addition, we explicitly tested how risk factors related to the two outcomes. Some variables showed a qualitative pattern. Native Hawaiian ethnicity was associated only with lower risk of chronicity. Several premilitary factors (age at entry, premilitary socioeconomic status, family instability) and aspects of the recovery environment (current instrumental assistance, post-Vietnam trauma) were associated only with the development of PTSD. Other variables showed a quantitative pattern, that is, they were associated with both outcomes, but were stronger predictors of developing PTSD. These variables included warzone exposure characteristics, peritraumatic dissociation, and aspects of the recovery environment (homecoming emotional sustenance, recent life events). Although individuals with lifetime PTSD had more of the given risk factors relative to individuals who never developed PTSD, those with current PTSD had even more than those whose PTSD had remitted.

Multivariate analyses found that it was possible to predict the development of PTSD on the basis of only a few variables. It also was possible to predict the maintenance of PTSD on the basis of a few variables, although the prediction was somewhat less adequate. We caution readers in interpreting these analyses as information about which variables are most "important" in understanding the etiology of PTSD on the basis of multivariate analyses of data, such as ours, in which predictors are correlated and potentially causal relationships exist among predictors. Although most of the intercorrelations were modest (e.g., $r=.17$ between age at Vietnam entry and education), and many variables were not related (e.g., $r=.02$ between structural social support and post-Vietnam trauma), multiple regression-especially with stepwise or simultaneous entry procedures-can obscure important predictors whose effects are indirect though other variables.

The higher likelihood of remission in Hawaiian and Japanese veterans, relative to White veterans, may be an artifact of the longer observation period in the HVVP. However, we think this explanation is insufficient. The National Comorbidity Survey found that remission among individuals with lifetime PTSD occurred up to 6 years following onset, with roughly one-third of cases unremitted thereafter (Kessler et al., 1995). Also, the pattern we observed for Native Hawaiians was similar to the pattern for Black veterans, who had a shorter observation period. Our analyses were not focused on exploring ethnic differences in risk and resilience, so we cannot say whether the profile of risk factors in the HVVP veterans facilitated recovery, or if Asian and Pacific Island cultural factors facilitated recovery. These would be useful questions for investigation.

Unlike Breslau and Davis (1992), we did not find that female gender was a risk factor for chronicity. Although our analyses differed from theirs, the most likely reason is the NVVRS data itself. Whereas most studies have found that female gender is associated with high probability of lifetime PTSD (e.g., Kessler et al., 1995; Stein et al., 1997), this is not true for the NVVRS (Kulka et al., 1990). A 
possible explanation is that most female Vietnam veterans served as nurses, who were older and had more education than men did at the time they went to Vietnam. We found that both factors were associated with lower likelihood of current PTSD. Replication of our findings with a different sample is needed before a firm conclusion can be drawn about the effect of gender on chronicity in military or nonmilitary populations.

Greater severity of warzone stressor exposure was strongly associated with both the development and maintenance of PTSD. For most warzone variables, the OR for the never/ever contrast was greater than the OR for the past/current contrast. As mentioned above, this suggests a quantitative relationship in how stressor characteristics relate to development and maintenance. Prior findings with Vietnam veterans had suggested a qualitative difference. Green et al. (1990) found that whereas a higher amount of combat exposure was related to the development of PTSD, particularly horrifying and life-threatening experiences were related to chronicity. Although methodological differences may explain the discrepancy, we note that atrocity exposure emerged in multivariate analysis as a predictor of maintaining PTSD, but not of developing PTSD - a finding consistent with Green and colleagues' study. Atrocity exposure may be associated with chronicity through shame, which may result from witnessing or participating in atrocities. A recent study found that shame measured 1 month following a trauma predicted a higher amount of PTSD symptoms at 6 months (Andrews, Brewin, Rose, \& Kirk, 2000). Our finding that serious injury was associated with chronicity is consistent with prospective studies that have found injury severity and the persistence of posttraumatic injury to predict chronic PTSD (Blanchard et al., 1997; Ehlers, Mayou, \& Bryant, 1998).

All characteristics of the postmilitary environment were associated with the development of PTSD. In contrast, the maintenance of PTSD was primarily associated with variables relating to the current time frame: current emotional sustenance, current structural social support, and recent life events. Emotional sustenance at homecoming was associated with both outcomes, but in multivariate analysis, emotional sustenance at homecoming predicted the development of PTSD and current emotional sustenance predicted the maintenance of PTSD. Low social support and posttraumatic life events were identified in a recent meta-analysis (Brewin et al., 2000) as having a particularly strong association with PTSD — weighted average $r \mathrm{~s}=.40$ and .32 , respectively. Neither this metaanalysis nor our study was designed to investigate the directionality of the relationship between the development and maintenance of PTSD and aspects of the recovery environment, which is likely to be complex and dynamic.
Hobfoll (1989) has proposed the concept of a loss spiral, in which lack of resources to offset losses initiated by a trauma leads to further loss. For example, insufficient social support might lead to the development of PTSD, and then numbing symptoms of PTSD might adversely affect social support and render an individual less able to deal with future stressors.

Depression with onset before, during, or after Vietnam was associated with the development of PTSD. Depression and other emotional difficulties prior to a trauma predispose individuals to develop PTSD (e.g., Blanchard et al., 1996; Breslau et al., 1991), and individuals often develop depression following the onset of PTSD (e.g., Kessler et al., 1995). Depression, regardless of onset, was not associated with the maintenance of PTSD, as had been expected on the basis of evidence that depression occurring in the months following a trauma predicts PTSD at 1 year (Freedman et al., 1999). The failure to confirm this finding may be due to our ability to date onset only by year, rather than month, as in Freedman et al.'s study, or to the difference between the observation periods in the two studies (1 year in Freedman et al. vs. up to more than 20 years in our study). Another factor may have been statistical power: the OR for onset during Vietnam as a predictor of current PTSD (2.66) was marginally significant.

We pooled full and partial cases of PTSD in order to increase statistical power. This is justified by evidence that PTSD is a dimensional rather than a categorical construct (Ruscio, Ruscio, \& Keane, 2002) and supported by the similarity of results across analyses that included versus excluded partial cases. Both sets of results imply that the development of PTSD is related to factors that occur before, during, and after a traumatic event, and the failure to recover from PTSD is related primarily to factors that occur during and after the event. Of course, statistical power must be considered when interpreting the lack of relationship between chronic PTSD and premilitary factors; power was greater for the never/ever PTSD contrast than for the past/current PTSD contrast. Yet power does not fully explain the lack of association between premilitary variables and chronic PTSD. For several premilitary variables - age at entry into Vietnam, premilitary socioeconomic status, and family instability - the OR for the past versus current contrast was close to 1.0 and there was a significant difference between the ORs for predicting the two outcomes.

Interpreting our findings in the context of other investigations is difficult because of differences in how PTSD was operationalized. For example, Brewin et al. (2000), in their meta-analysis of risk factors for PTSD, pooled studies that examined current or lifetime PTSD. Nevertheless, 
the largest effect sizes were associated with peritraumatic or posttraumatic risk factors, relative to pretraumatic factors. King et al. (1999) used structural equation modeling to examine the relative contributions of premilitary, military, and postmilitary risk factors to predicting current PTSD and found that premilitary variables had the smallest total effect on current PTSD in both men and women. This also is consistent with our findings, although King et al.'s study design does not permit a strict comparison.

More relevant are investigations that have compared current and remitted cases of PTSD, or that have looked at the predictive value of risk factors for PTSD assessed at different intervals following traumatic exposure. Most studies, including ours, have found that chronicity is related primarily to peritraumatic and posttraumatic factors, compared with pretraumatic factors (e.g., Blanchard et al., 1997; Ehlers et al., 1998). Particularly interesting are studies that suggest the cognitive processing of traumatic material as a key factor in the maintenance of PTSD (Dunmore et al., 1999, 2001; Ehlers et al., 1998). Ehlers and Clark (2000) proposed that the maintenance of PTSD is associated with a style of cognitive processing that leads to trauma being represented as a serious ongoing threat. They proposed that cognitive processing and appraisals of a traumatic event are influenced by characteristics of the event and state factors such as alcohol consumption or arousal, as well as low intelligence and prior beliefs and experiences. It is obvious that some of these influences are pretraumatic. Hence, it is inappropriate to conclude that pretraumatic variables are unimportant, or less important, than peritraumatic and posttraumatic variables in the maintenance of PTSD. Pretraumatic variables may appear weakly related to PTSD because the effects of these variables are mediated through peritraumatic or posttraumatic variables (Brewin et al., 2000). However, this explanation cannot account for our univariate findings showing that few pretraumatic variables were risk factors for the maintenance of PTSD; mediators cannot mediate the effects of predictors that are unrelated to an outcome.

Future investigations of risk factors for chronicity should include measures of the cognitive variables suggested by Ehlers and Clark (2000). Measures of pretraumatic personality should be included because traits such as negative affectivity are consistently associated with PTSD (Schnurr \& Vielhauer, 1999) and negative affectivity (and other traits) conceivably could affect the cognitive processes hypothesized by Ehlers and Clark to increase the persistence of PTSD.

The correlational nature of our design does not permit causal inferences. A preferable way to address the questions we have posed is through prospective studies of recently traumatized individuals (e.g., Blanchard et al., 1997; Freedman et al., 1999). We did not have variables that capture important psychological processes in recovery, such as rumination (e.g., Dunmore et al., 2001; Ehlers et al., 1998). Another limitation is that our results may generalize primarily to military veterans. Some risk factors differ in their association with PTSD across military and civilians samples (Brewin et al., 2000). Also, among men, chronicity is more likely for combat than for other traumas (Prigerson, Maciejewski, \& Rosenheck, 2001).

Despite these limitations, our study has methodological advantages as well: a comparison of current and remitted PTSD cases, an ethnically diverse sample, and an analytic method that compared how risk factors separately relate to the development and maintenance of PTSD. Identifying who will develop PTSD is an important step in intervention. Identifying who is unlikely to recover may further intervention efforts and help minimize the chronicity of PTSD in trauma survivors.

\section{Acknowledgments}

The research reported here was supported by a Merit Review grant from the Department of Veterans Affairs. We thank Chris Brewin for helpful comments on the manuscript and Dan and Lynda King for consultation on the selection and creation of variables for analysis.

\section{References}

Andrews, B., Brewin, C. R., Rose, S., \& Kirk, M. (2000). Predicting PTSD symptoms in victims of violent crime: The role of shame, anger, and childhood abuse. Journal of Abnormal Psychology, 109, 69-73.

Blanchard, E. B., Hickling, E. J., Forneris, C. A., Taylor, A. E., Buckley, T. C., Loos, W. R., et al. (1997). Prediction of remission of acute posttraumatic stress disorder in motor vehicle accident victims. Journal of Traumatic Stress, 10, 215-234.

Blanchard, E. B., Hickling, E. J., Taylor, A. E., Loos, W. R., Forneris, C. A., \& Jaccard, J. (1996). Who develops PTSD from motor vehicle accidents? Behaviour Research and Therapy, 34, 1-10.

Breslau, N., \& Davis, G. C. (1992). Posttraumatic stress disorder in a urban population of young adults: Risk factors for chronicity. American Journal of Psychiatry, 149, 671-675.

Breslau, N., Davis, G. C., Andreski, P., \& Peterson, E. (1991). Traumatic events and posttraumatic stress disorder in an urban population of young adults. Archives of General Psychiatry, 48, 216-222.

Brewin, C. R., Andrews, B., \& Valentine, J. D. (2000). Meta-analysis of risk factors for posttraumatic stress disorder in trauma-exposed adults. Journal of Consulting and Clinical Psychology, 68, 748766.

Dunmore, E., Clark, D. M., \& Ehlers, A. (1999). Cognitive factors involved in the onset and maintenance of posttraumatic stress disorder (PTSD) after physical or sexual assault. Behaviour Research and Therapy, 37, 809-829. 
Dunmore, E., Clark, D. M., \& Ehlers, A. (2001). A prospective examination of the role of cognitive factors in persistent posttraumatic stress disorder (PTSD) after physical or sexual assault. Behaviour Research and Therapy, 39, 1063-1084.

Ehlers, A., \& Clark, D. M. (2000). A cognitive model of posttraumatic stress disorder. Behaviour Research and Therapy, 38, 319345.

Ehlers, A., Mayou, R. A., \& Bryant, B. (1998). Psychological predictors of chronic posttraumatic stress disorder after motor vehicle accidents. Journal of Abnormal Psychology, 107, 508-519.

Freedman, S. A., Brandes, D., Peri, T., \& Shalev, A. (1999). Predictors of chronic post-traumatic stress disorder: A prospective study. British Journal of Psychiatry, 174, 353-359.

Friedman, M. J., Ashcraft, M. L., Beals, J. L., Keane, T. M., Manson, S. M., \& Marsella, A. J. (1997). Matsunaga Vietnam Veterans Project. White River Junction, VT: VA National Center for PTSD.

Green, B. L., Grace, M. C., Lindy, J. D., \& Gleser, G. C. (1990). War stressors and symptom persistence in posttraumatic stress disorder. Journal of Anxiety Disorders, 4, 31-39.

Hobfoll, S. (1989). Conservation of resources: A new attempt at conceptualizing stress. American Psychologist, 44, 513-524.

Hosmer, D. W., \& Lemeshow, S. (2000). Applied logistic regression (2nd ed.). New York: Wiley.

Kessler, R. C., Sonnega, A., Bromet, E., Hughes, M., \& Nelson, C. B. (1995). Posttraumatic stress disorder in the National Comorbidity Survey. Archives of General Psychiatry, 52, 1048-1060.

King, D. W., King, L. A., Foy, D. W., \& Gudanowski, D. M. (1996). Prewar factors in combat-related posttraumatic stress disorder: Structural equation modeling with a national sample of female and male Vietnam veterans. Journal of Consulting and Clinical Psychology, 64, 520-531.

King, D. W., King, L. A., Foy, D. W., Keane, T. M., \& Fairbank, J. A. (1999). Posttraumatic stress disorder in a national sample of female and male Vietnam veterans: Risk factors, war-zone stressors, and resilience-recovery variables. Journal of Abnormal Psychology, 108, 164-170.

King, L. A., King, D. W., Fairbank, J. A., Keane, T. M., \& Adams, G. A. (1998). Resilience/recovery factors in posttraumatic stress disorder among female and male Vietnam veterans: Hardiness, postwar social support, and additional stressful life events. Journal of Personality and Social Psychology, 74, 420-434.

Kulka, R. A., Schlenger, W. E., Fairbank, J. A., Hough, R. L., Jordan, B. K., Marmar, C. R., et al. (1990). Trauma and the Vietnam War generation: Report of findings from the National Vietnam Veterans Readjustment Study. New York: Brunner/Mazel.

Marmar, C. R., Weiss, D. S., Schlenger, W. E., Fairbank, J. A., Jordan, B. K., Kulka, R. A., et al. (1994). Peritraumatic dissociation and posttraumatic stress in male Vietnam theater veterans. American Journal of Psychiatry, 151, 902-907.

McFarlane, A. C. (1988). The longitudinal course of posttraumatic morbidity: The range of outcomes and their predictors. Journal of Nervous and Mental Disease, 176, 30-39.

McFarlane, A. C. (1992). The phenomenology of posttraumatic stress disorders following a natural disaster. Journal of Nervous and Mental Disease, 180, 22-29.

North, C. S., Smith, E. M., \& Spitznagel, E. L. (1997). One-year followup of survivors of a mass shooting. American Journal of Psychiatry, 154, 1696-1702.

Prigerson, H. G., Maciejewski, P. K., \& Rosenheck, R. A. (2001). Combat trauma: Trauma with highest risk of delayed onset and unresolved posttraumatic stress disorder symptoms, unemployment, and abuse among men. Journal of Nervous and Mental Disease, 189, 99-108.

Resnick, H. S., Kilpatrick, D. G., Dansky, B. S., Saunders, B. E., \& Best, C. L. (1993). Prevalence of civilian trauma and posttraumatic stress disorder in a representative national sample of women. Journal of Consulting and Clinical Psychology, 61, 984-991.

Ruscio, A. M., Ruscio, J., \& Keane, T. M. (2002). The latent structure of posttraumatic stress disorder: A taxometric investigation of reactions to extreme stress. Journal of Abnormal Psychology, 111, 290-301.

Schnurr, P. P., Friedman, M. J., \& Rosenberg, S. D. (1993). Premilitary MMPI scores as predictors of combat-related PTSD symptoms. American Journal of Psychiatry, 150, 479-483.

Schnurr, P. P., Lunney, C. A., Sengupta, A., \& Waelde, L. (2003). A descriptive analysis of PTSD subtypes among Vietnam veterans. Journal of Traumatic Stress, 16, 545-553.

Schnurr, P. P., \& Vielhauer, M. (1999). Personality as a risk factor in the development of PTSD. In R. Yehuda (Ed.), Risk factors for PTSD (pp. 191-222). Washington, DC: American Psychiatric Association.

Spitzer, R. L., Williams, J. B., Gibbon, M., \& First, M. B. (1989). Structured Clinical Interview for DSM-III-R. New York: Biometrics Research Department, New York State Psychiatric Institute.

Stein, M. B., Walker, J. R., Hazen, A. L., \& Forde, D. R. (1997). Full and partial posttraumatic stress disorder: Findings from a community survey. American Journal of Psychiatry, 154, 1114-1119. 